intake) and asking for help.

Discussion: Implementation of the project requires caring and commitment, rather than resources. Children with chronic illnesses must have equal access to education.

Conclusion: This project needs widening to be conducted in all schools where diabetic children study.

\title{
PO11 - S.O.S. infant's crying! An educational path in a paedatric counselling context
}

Federica Logrippo (Italy) ${ }^{1}$; Emanuela Berbotto (Italy) ${ }^{1}$; Marina

Remon (Italy)2; Anna Persico (Italy) ${ }^{1}$

${ }^{1}$ University of Turin; ${ }^{2}$ Pediatria di comunità, Asltol

Theme: Parenting/parenthood.

Keywords: Crying, empowerment, infant, parents.

Introduction: In Western societies, an infant's crying often causes anxiety in parents. Educational and empowerment paths of parenthood could be useful to overcome these difficulties (Hiscock 2004).

Aims: Design and implement a pilot test of an educational path with a group of infants' (0-3 months) parents to support them in the acceptance of their children's crying and develop coping strategies.

Methods: The pilot test is composed by two meeting with 8 parents in a paediatric counselling situation. It's based on an empowerment's model of parenthood. The tools are brainstorming and narrations; they are used to analyze intervention's needs and to accompany parents in accepting children's crying.

Results: The first narrations underline parents' need to take on the topic and to be valued in their parental role; from the second ones it comes out that the parents appreciate the project.

Conclusions: The pilot test was completed and appreciated by the parents.

\section{P012 - The Fuller's Infants Pain Assessment Scale utility in practice in the opinion of the nurses working in Tartu University Hospital}

Merle Seera Rn, Msc (Estonia) ${ }^{1}$

${ }^{1}$ Reet Kikas MD

Theme: Child protection and managing risk.

Keywords: Infants, pain management.

Aim: The aim of this study was to describe nurses' opinion on a Fuller's Infants Pain 